\title{
Development of an electronic frailty index for predicting mortality in patients undergoing transcatheter aortic valve replacement using machine learning
}

\section{Running title: electronic frailty index for TAVR}

Yiyi Chen MSc $*^{1}$, Jiandong Zhou MSc $*^{2}$, Sharen Lee ${ }^{3}$, Tong Liu MD PhD ${ }^{4}$, Sandeep S Hothi PhD FACC FESC FRCP ${ }^{5}$, Ian Chi Kei Wong $\mathrm{PhD}^{6}$, Qingpeng Zhang $\mathrm{PhD}^{2}$, Gary

Tse PhD FACC FSCAI FRCP ${ }^{3,4,7}$, Yan Wang MD PhD FACC FSCAI ${ }^{7}$

${ }^{1}$ Research Department of Practice and Policy, School of Pharmacy, University College London, London, London, UK

${ }^{2}$ School of Data Science, City University of Hong Kong, Hong Kong, China

3 Laboratory of Cardiovascular Physiology, Li Ka Shing Institute of Health Sciences, Faculty of Medicine, The Chinese University of Hong Kong, Hong Kong, China

${ }^{4}$ Tianjin Key Laboratory of Ionic-Molecular Function of Cardiovascular disease, Department of Cardiology, Tianjin Institute of Cardiology, Second Hospital of Tianjin Medical

University, Tianjin 300211, China

${ }^{5}$ Heart and Lung Centre, New Cross Hospital, Wolverhampton, UK

${ }^{6}$ Department of Pharmacology and Pharmacy, University of Hong Kong, Pokfulam, Hong Kong, China

${ }^{7}$ Xiamen Cardiovascular Hospital, Xiamen University, Xiamen, China

* Joint first authors

Correspondence to:

Dr. Qingpeng Zhang PhD

School of Data Science, City University of Hong Kong,

Hong Kong, China

Email: qingpeng.zhang@cityu.edu.hk

Dr. Gary Tse, PhD, FRCP, FFPH

Tianjin Key Laboratory of Ionic-Molecular Function of Cardiovascular Disease, Department of Cardiology, Tianjin Institute of Cardiology, Second Hospital of Tianjin Medical University, Tianjin 300211

Xiamen Cardiovascular Hospital, Xiamen University, Xiamen, China

Email: gary.tse@doctors.org.uk

Word count: 2376 words

Key words: electronic frailty index; transaortic valvular replacement; mortality; machine learning 


\begin{abstract}
Background: Electronic frailty indices can be useful surrogate measures of frailty. We assessed the role of machine learning to develop an electronic frailty index, incorporating demographics, baseline comorbidities, healthcare utilization characteristics, electrocardiographic measurements, and laboratory examinations, and used this to predict allcause mortality in patients undergoing transaortic valvular replacement (TAVR).
\end{abstract}

Methods: This was a multi-centre retrospective observational study of patients undergoing for TAVR. Significant univariate and multivariate predictors of all-cause mortality were identified using Cox regression. Importance ranking of variables was obtained with a gradient boosting survival tree (GBST) model, a supervised sequential ensemble learning algorithm, and used to build the frailty models. Comparisons were made between multivariate Cox, GBST and random survival forest models.

Results: A total of 450 patients (49\% females; median age at procedure 82.3 (interquartile range, IQR 79.0-86.0)) were included, of which 22 died during follow-up. A machine learning survival analysis model found that the most important predictors of mortality were APTT, followed by INR, severity of tricuspid regurgitation, cumulative hospital stays, cumulative number of readmissions, creatinine, urate, ALP, and QTc/QT intervals. GBST significantly outperformed random survival forests and multivariate Cox regression (precision: 0.91, recall: 0.89, AUC: 0.93, C-index: 0.96, and KS-index: 0.50) for mortality prediction.

Conclusions: An electronic frailty index incorporating multi-domain data can efficiently predict all-cause mortality in patients undergoing TAVR. A machine learning survival learning model significantly improves the risk prediction performance of the frailty models. 


\section{Introduction}

Aortic stenosis (AS), reduction in the effective orifice area of the semilunar cardiac valve at the interface of the left ventricle and the systemic arterial circulation, is a significant medical problem globally ${ }^{1}$. AS has a prevalence of 2-9\% of the population over 65 years and $4 \%$ in those who are over $85^{2}$. It is associated with aging and confers a poor prognosis ${ }^{3}$. There are different types of operations for the treatment of AS. Of these, transcatheter aortic valve replacement (TAVR) is a less invasive alternative to surgical aortic valve replacement for patients with severe, symptomatic AS, especially for those who are at high risk or intermediate risk of adverse events, e.g. those with a high number of comorbidities ${ }^{4}$. Moreover, recent work has found that TAVR in low-risk patients is noninferior to surgical management ${ }^{5}$.

TAVR has been shown to have a satisfactory efficacy and safety and recommendations by guidelines from various international societies ${ }^{6,7}$. However, recent studies have found that frailty is a common finding in AS patients and is associated with increased mortality. Approximately half of patients who undergo TAVR die within four years of the procedure ${ }^{8}$. It is therefore crucial to weigh up risks and benefits before when offering TAVR to patients, in particular, trying to select those in whom the procedure is likely to confer greater gains in symptoms and prognosis, and identifying those who may not benefit, or indeed suffer harm, following TAVR.

Machine learning techniques have been widely applied in medical research. Specifically, a gradient boosting survival tree model has recently been explored as an efficient method for diagnosing coronary artery disease ${ }^{9}$. In this territory-wide study, we tested the hypothesis that an electronic frailty index incorporating demographics, baseline comorbidities, healthcare utilization characteristics, electrocardiographic measurements, and 
laboratory examinations using a gradient boosting approach can improve risk prediction for all-cause mortality.

\section{Methods}

Study design

This study was approved by The Joint Chinese University of Hong Kong - New Territories East Cluster Clinical Research Ethics Committee. This retrospective study included patients undergoing TAVR. Patients were identified from the Clinical Data Analysis and Reporting System (CDARS), a healthcare database that integrates patient information across all 43 publicly funded hospitals and their associated ambulatory and primary care facilities in Hong Kong to establish comprehensive medical records. The available information includes demographics, clinical characteristics, disease diagnoses, laboratory examinations, drug prescription details, and admission statistics.

\section{Data extraction and variables}

The following data were extracted: 1) Baseline characteristics of gender, age at TAVR, age at first presentation with AS, TR severity, AR severity, MR severity, PR severity, complete recovery status, INR on the day of TAVR procedure; 2) baseline comorbidities including bradyarrhythmia, atrial fibrillation/flutter, tachyarrhythmia, diabetes mellitus, hypertension, hyperlipidaemia, respiratory diseases, kidney diseases, endocrine disorders (other than diabetes mellitus) and gastrointestinal diseases using corresponding ICD-9 codes; 3) ECG measurements of ventricular rate, P-wave duration (PWD), PR interval, QRS duration, QT interval, corrected QT interval (QTc), P-wave axis, QRS axis, T-wave axis, R- 
wave amplitude in V5, and S-wave amplitude in V1; 4) healthcare utilization characteristics before TAVR presentation: cumulative hospital stay, cumulative number of hospital readmissions, and number of emergency readmissions (within 28 days of discharge); 5) laboratory tests: complete blood count, liver function tests, renal function tests. Details of ICD codes used for comorbidity identification are provided in the Supplementary Appendix.

\section{Primary outcome and statistical analysis}

The primary outcome was all-cause mortality. Descriptive statistics were presented for the overall cohort and categorized based on mortality status. Continuous variables were presented as median (95\% confidence interval $[\mathrm{CI}]$ or interquartile range $[\mathrm{IQR}]$ ) and categorical variables were presented as counts (\%). The Mann-Whitney U test was used to compare continuous variables. The $\chi^{2}$ test with Yates' correction was used for $2 \times 2$ contingency data, and Pearson's $\chi^{2}$ test was used for contingency data for variables with more than two categories. To evaluate the significant prognostic risk factors associated with disease group status and primary outcomes, univariate Cox regression models were used with adjustments based on baseline characteristics. Significant univariable predictors were used as inputs in a multivariate Cox regression model to avoid overfitting. Hazard ratios (HRs) with corresponding 95\% CIs and P values were reported accordingly. All significance tests were two-tailed and considered statistically significant if $\mathrm{P}$ values were 0.05 . Data analyses were performed using RStudio software (Version: 1.1.456) and Python (Version: 3.6). Simulations were performed were using a 15-inch MacBook Pro with $2.2 \mathrm{GHz}$ Intel Core i7 Processor and 16 GB RAM (Hong Kong, China). 


\section{Development of a gradient boosting survival tree model}

Survival analysis is a statistical method to deal with lifetime data, where the outcome is the time to occurrence of an event of interest, such as mortality. The most widely applied survival analysis model in biostatistics is the Cox proportional hazards model ${ }^{10}$. Gradient boosting, a class of machine learning methods, was developed based on the concept that a tree-based model after being sequentially combined with previous weak models (e.g. decision trees) in a stage-wise way can generate superior predictions for survival and other outcomes. Tree-structured survival models such as survival trees ${ }^{11}$ and random survival forests ${ }^{12}$ have been used to determine survival probabilities in medical studies.

This inspired us to use a nonparametric ensemble tree model called a gradient boosting survival tree (GBST) that extends the survival tree models with the concept of gradient boosting ${ }^{13}$. GBST optimizes the survival probability of each time period simultaneously and therefore is able to significantly reduce the overall prediction error of a survival tree. In this study, GBST was used for mortality risk prediction of patients undergoing TAVR. A tree-structure based approach for ranking the importance value of different variables was used, to construct a machine learning based, electronic frailty index for predicting mortality outcome. To examine the GBST performance of survival risk discrimination and compare it with baseline models of random survival forests and a multivariate Cox regression model, we adopted a five-fold cross validation approach. The concordance index (C Index) proposed by Harrell et al. (1982) was used to measure the goodness of fit for the survival model, as the statistic provides a global assessment of the model for the continuous event. The territory-wide cohort dataset also guarantees the c-Index not to be limited by censoring. We applied the c-index introduced above as well as a precision, recall, Kolmogorov-Smirnov (KS) index and the area under the receiver operating characteristics curve (AUC) to measure the goodness of model fit. The R packages, gbm 
(Version 2.1.5), randomForestSRC (Version 2.9.3), survival (Version 2.42-3) and ggplot2 (Version 3.3.2), were used to generate the mortality prediction results.

\section{Results}

\section{Baseline cohort characteristics}

The baseline characteristics of this cohort of patients undergoing TAVR are shown in

Table 1. A total of 450 patients were included (female 49\%; mean age at time of procedure: 82.3 (IQR 79.0-86.0) years; median age at first hospital presentation:79 (IQR: 74.0-83.0)) years. A total of 22 deaths (32\% female) occurred during follow-up. The Kaplan-Meier survival curve of patients undergoing TAVR is shown in Figure 1.

Further comparisons were made between the deceased and alive subgroups. Patients who died had an older age (83.8, IQR: [81.0-87.0] vs. 82.1, IQR: [79.0-86.0]) years, higher INR at procedure (1.32, IQR: 1.07-2.39 vs. 1.07, IQR: [1.0-1.17]). The presence of diabetes mellitus and hypertension were the most common comorbidities, followed by respiratory, gastrointestinal, and kidney diseases, atrial fibrillation/flutter, and hyperlipidaemia. In terms of healthcare utilization, those who died had a longer median inhospital length-of-stay (53 days, IQR: [10.0-121.0] vs. 18 days, IQR: [6.0-46.0]), higher median number of hospital admissions (12, IQR: [4.0-23.0] vs. 9, IQR: [4.0-15.0]) and median number of emergency readmissions within 28 days after discharge (2.5, IQR: [1.0-6.0] vs. 2, IQR: [1.0-4.0]) before the TAVR procedure.

Regarding laboratory examinations, those who died had larger mean corpuscular volume (91.4 fL, IQR: [88.0-96.0]), higher mean corpuscular haemoglobin $\left(33.9 \times 10^{\wedge} 9 / \mathrm{L}\right.$, IQR: [33.0-34.0]), higher haematocrit (0.399, L/L, IQR: [0.3805-0.4095]), higher neutrophil count (4.2 $\times 10^{\wedge} 9 / \mathrm{L}$, IQR: [3.0-6.0]), higher monocyte count $\left(0.5 \times 10^{\wedge} 9 / \mathrm{L}, \mathrm{IQR}:[0.34-0.6]\right)$ and longer APTT (15.2 secs, IQR: [12.0-19.0]). By contrast, they had lower lower red blood 
cell (50.6 x10^12/L, IQR: [44.0-77.0]), white blood cell (median: 6.1 x10^9/L, IQR: [5.08.0]), eosinophil (0.125 x10^9/L, IQR: [0.0745-0.275]), lymphocyte (1.08 x10^9/L, IQR: [0.81-1.48]), blast (0.045 x10^9/L, IQR: [0.0-0.065]), metamyelocyte (0.09 x10^9/L, IQR: [0.055-0.165]) and myelocyte counts $\left(0.17 \times 10^{\wedge 9 / L, ~ I Q R: ~}[0.13-0.555]\right)$ as well as lower platelet counts $\left(152.5 \times 10^{\wedge} 9 / \mathrm{L}, \mathrm{IQR}:\right.$ [130.0-195.0]) compared to those who remained alive (Table 1).

Moreover, they had higher potassium (4.4 mmol/L, IQR: [4.0-4.8]), urate $(0.43$ mmol/L, IQR: [0.36-0.48]), urea (6.6 mmol/L, IQR: [6.0-10.0]), protein (73.2 g/L, IQR: [67.0-76.0]), creatinine (105.9 umol/L, IQR: [78.0-150.0]), alkaline phosphatase (73.5 U/L, IQR: [64.0-91.0]) and bilirubin levels (13, umol/L, IQR: [9.0-19.0]), but lower sodium (140 mmol/L, IQR: [140.0-142.0]), albumin (38.9 g/L, IQR: [36.0-41.0]), aspartate transaminase (median: 24.8 U/L, IQR: [22.0-32.0]) as well as HbA1c levels (12 g/dL, IQR: [11.0-13.0]).

In terms of ECG measurements, patients who died had higher basal ventricular rate $(95$, IQR: [78-109] vs. 78 bpm, IQR: [68-92]), lower P-wave durations (90, IQR: [90-90] vs. 120 ms, IQR: [109-127]). PR interval, QTc interval and QRS axis were all significantly larger, whereas QRS duration, QT interval, P-wave axis, T-wave axis, R-wave amplitude in V5 and S-wave amplitude in V1 were lower in those who died compared to those who were alive (Table 1).

\section{Predictors of mortality and frailty model}

Univariate Cox regression analysis was performed to identify significant predictors of all-cause mortality (Table 2). This identified severe tricuspid regurgitation (hazard ratio [HR]: 8.93, 95\%CI: [3.22, 24.78], $\mathrm{p}<0.0001$ ), international normalized ratio (HR: 2.74, 95\%

CI: [1.84, 4.09], $\mathrm{p}<0.0001$ ), cumulative hospital length-of-stay (HR: 1.01, 95\% CI: [1.00, 1.01], $\mathrm{p}=0.0008$ ), aspartate transaminase (HR: $1.01,95 \% \mathrm{CI}:[0.98,1.002], \mathrm{p}=0.0002 * * *)$, 
and bilirubin (HR: 1.02, 95\% CI: [1.01, 1.02], $\mathrm{p}=0.0003 * * *)$ as predictors of all-cause mortality. Subsequently, important variables $(\mathrm{HR} \geq 1)$ were included in a multivariate regression analysis (Table 3). Severe tricuspid regurgitation, INR, haematocrit and potassium were significant predictors after adjustment $(\mathrm{P}<0.001)$.

\section{Results of machine learning survival analysis and frailty score construction}

The tree number in the GBST model was set to 320 according to the sensitivity analysis results (Supplementary Figure 1), where the association of Cox partial deviance versus the number of trees within the gradient boosting tree structure was depicted. The green line shows the validation deviance versus iteration number, with iteration almost stabilizing around the deviance value of 6.3 when one thousand trees were used. The black line shows the training error versus the iteration number. The optimal tree number was set according to the dashed blue line (validation).

With the input of important risk predictors identified by univariate Cox regression analysis, variable importance ranking is obtained by performing the introduced GBST model (Supplementary Figure 2) with the values shown in Supplementary Table 2. APTT showed the most important strength, followed by INR, severe TR status, cumulative inhospital length-of-stay, cumulative number of hospital admissions, creatinine, urate, ALP, QTc and QT intervals.

Five-fold cross validation experiments were conducted on the dataset using GBST, RSF, and multivariate Cox regression (Supplementary Table 3). GBST showed the best survival prediction performance over RSF and multivariate Cox model according to evaluation metrics of precision, recall, AUC, C-Index, and KS-Index. The advantage of the GBST model stems from its ability to sequentially add weak decision tree learning models to the 
ensemble model, which can correct the prediction errors of prior models to minimize the overall prediction error. The predicted out-of-bag (OOB) survivals and cumulative hazards with the introduced GBST model are shown in Supplementary Figure 3.

\section{Discussion}

The main findings of this territory-wide study of patients undergoing TAVR are twofold. Firstly, patient demographics, comorbidities, healthcare utilization statistics prior to the procedure, laboratory examinations and ECG measurements were significant predictors of mortality. Secondly, a nonparametric gradient boosting survival tree model outperformed random survival forest model and multivariate Cox regression model for all-cause mortality prediction.

Frailty has been shown to be a strong predictor of adverse outcomes in patients with heart failure, and in those undergoing cardiac interventional procedures ${ }^{14-20}$. Specifically related to TAVR, previous studies have examined the value of determining frailty for risk stratification. For example, a study in 2018 showed that $11 \%$ patients of average age of 83 died 2 years after TAVR, and a geriatric assessment frailty score cut-off at $\geq 4$ predicted 2 year mortality with a specificity of $80 \%^{21}$. Another study showed that 242 out of 544 TAVR patients were frail 1 year after the procedure based on frailty definition ${ }^{22}$.

However, in clinical situations, it may be impractical to fully assess frailty status of patients and surrogates that can accurately model or reflect frailty would save time for patient assessment. Therefore, clinician-researchers have designed the electronic frailty index based on the concept that frailty is caused by the accumulation of health deficits ${ }^{23}$. Segal et al. designed the electronic frailty index by selecting candidate variables based on their potential correlations with frailty state rather than mortality directly ${ }^{24}$. An electronic frailty index has 
been used as an efficient variable to predict mortality in TAVR ${ }^{25}$. In our territory-wide cohort, we developed an electronic frailty index based on predictors that were identified by Cox regression analysis and showed that this can predict all-cause mortality in patients undergoing TAVR.

Survival analysis has been widely used in clinical and epidemiological studies based on electronic health records (EHRs) that provide rich and diverse information for modelling and prediction. Survival analysis models in the literature may be parametric or semiparametric, including survival tree analysis in the context of conditional inference trees ${ }^{26}$, survival forest analysis considering inverse probability of censoring weighting to compensate censoring ${ }^{27}$, random survival forest model with log-rank test ${ }^{12}$, censoring unbiased regression trees and forests with censoring unbiased loss functions ${ }^{28}$, ensemble tree method for right-censored survival data ${ }^{29}$. Traditional Cox proportional hazard models are used to identify the linear combinations. Tree structure-based survival analysis models have been widely applied in medical studies such as mortality prediction in systolic heart failure ${ }^{30}$. In our study, we demonstrated that a nonparametric gradient boosting survival tree model significantly improved mortality prediction in patients undergoing TAVR.

\section{Conclusions}

An electronic frailty index incorporating multi-domain data can efficiently predict allcause mortality in patients undergoing TAVR. A machine learning-drive survival model significantly improves the risk prediction performance of the frailty models.

\section{Acknowledgements}

None. 


\section{Funding}

None.

\section{Data availability}

The data underlying this article will be shared on reasonable request to the corresponding author.

\section{Conflicts of Interest}

All authors declare no conflict of interest.

\section{References}

1. Harris C, Croce B, Phan K. Aortic stenosis. Ann Cardiothorac Surg 2015;4(1):99.

2. Faggiano $\mathrm{P}$, Antonini-Canterin F, Baldessin F, Lorusso R, D'Aloia A, Cas LD. Epidemiology and cardiovascular risk factors of aortic stenosis. Cardiovasc Ultrasound 2006;4:27.

3. Fattouch K, Castrovinci S, Carita P. Aortic valve stenosis: treatments options in elderly high-risk patients. J Geriatr Cardiol 2016;13(6):473-4.

4. Afilalo J, Lauck S, Kim DH, Lefevre T, Piazza N, Lachapelle K, Martucci G, Lamy A, Labinaz M, Peterson MD, Arora RC, Noiseux N, Rassi A, Palacios IF, Genereux P, Lindman BR, Asgar AW, Kim CA, Trnkus A, Morais JA, Langlois Y, Rudski LG, Morin JF, Popma JJ, Webb JG, Perrault LP. Frailty in Older Adults Undergoing Aortic Valve Replacement: The FRAILTY-AVR Study. J Am Coll Cardiol 2017;70(6):689-700.

5. Popma JJ, Deeb GM, Yakubov SJ, Mumtaz M, Gada H, O'Hair D, Bajwa T, Heiser JC, Merhi W, Kleiman NS, Askew J, Sorajja P, Rovin J, Chetcuti SJ, Adams DH, Teirstein PS, Zorn GL, 3rd, Forrest JK, Tchetche D, Resar J, Walton A, Piazza N, Ramlawi B, Robinson N, Petrossian G, Gleason TG, Oh JK, Boulware MJ, Qiao H, Mugglin AS, Reardon MJ, Evolut Low Risk Trial I. Transcatheter Aortic-Valve Replacement with a Self-Expanding Valve in Low-Risk Patients. N Engl J Med 2019;380(18):1706-1715.

6. Nishimura Rick A, Otto Catherine M, Bonow Robert O, Carabello Blase A, Erwin John P, Fleisher Lee A, Jneid H, Mack Michael J, McLeod Christopher J, O'Gara Patrick T, Rigolin Vera H, Sundt Thoralf M, Thompson A. 2017 AHA/ACC Focused Update of the 2014 AHA/ACC Guideline for the Management of Patients With Valvular Heart Disease: A Report of the American College of Cardiology/American Heart Association Task Force on Clinical Practice Guidelines. Circulation 2017;135(25):e1159-e1195.

7. Baumgartner H, Falk V, Bax JJ, De Bonis M, Hamm C, Holm PJ, lung B, Lancellotti P, Lansac E, Rodriguez Muñoz D, Rosenhek R, Sjögren J, Tornos Mas P, Vahanian A, Walther T, Wendler O, Windecker S, Zamorano JL, Group ESCSD. 2017 ESC/EACTS Guidelines for the management of valvular heart disease. European Heart Journal 2017;38(36):2739-2791. 
8. Salinas P, Moreno R, Calvo L, Sanchez-Recalde A, Jimenez-Valero S, Galeote G, Lopez-Fernandez T, Ramirez U, Riera L, Plaza I, Moreno I, Mesa JM, Lopez-Sendon JL. Long-term Follow-up After Transcatheter Aortic Valve Implantation for Severe Aortic Stenosis. Rev Esp Cardiol (Engl Ed) 2016;69(1):37-44.

9. Yuan X, Wang X, Han J, Liu J, Chen H, Zhang K, Ye Q. A High Accuracy Integrated Bagging-Fuzzy-GBDT Prediction Algorithm for Heart Disease Diagnosis. In: 2019 IEEE/CIC International Conference on Communications in China (ICCC). 2019, p. 467-471.

10. Blakely RJ, Cox A. Evidence for short geomagnetic polarity intervals in the Early Cenozoic. Journal of Geophysical Research (1896-1977) 1972;77(35):7065-7072.

11. Gordon L, Olshen RA. Tree-structured survival analysis. Cancer Treat Rep 1985;69(10):1065-9.

12. Ishwaran H, Kogalur UB, Blackstone EH, Lauer MS. Random survival forests. Ann. Appl. Stat. 2008;2(3):841-860.

13. Chen $Y$, Jia Z, Mercola D, Xie X. A gradient boosting algorithm for survival analysis via direct optimization of concordance index. Comput Math Methods Med 2013;2013:873595.

14. Mlynarska A, Mlynarski R, Marcisz C, Golba KS. Modified Frailty as a Novel Factor in Predicting the Maintenance of the Sinus Rhythm After Electrical Cardioversion of Atrial Fibrillation in the Elderly Population. Clin Interv Aging 2020;15:1193-1199.

15. Fumagalli S, Pelagalli G, Montorzi RF, Marozzi I, Migliorini M, D'Andria MF, Lip GYH, Marchionni N. The CHA2DS2-VASc score and Geriatric Multidimensional Assessment tools in elderly patients with persistent atrial fibrillation undergoing electrical cardioversion. A link with arrhythmia relapse? Eur J Intern Med 2020.

16. Goel NJ, lyengar A, Kelly JJ, Han JJ, Brown CR, Desai ND. Volume of frail patients predicts outcome in frail patients after cardiac surgery. J Thorac Cardiovasc Surg 2020.

17. Zhang Y, Yuan M, Gong M, Li G, Liu T, Tse G. Associations Between Prefrailty or Frailty Components and Clinical Outcomes in Heart Failure: A Follow-up Meta-analysis. J Am Med Dir Assoc 2019;20(4):509-510.

18. Zhang Y, Yuan M, Gong M, Tse G, Li G, Liu T. Frailty and Clinical Outcomes in Heart Failure: A Systematic Review and Meta-analysis. J Am Med Dir Assoc 2018;19(11):1003-1008 e1.

19. Tse G, Gong M, Wong SH, Wu WKK, Bazoukis G, Lampropoulos K, Wong WT, Xia Y, Wong MCS, Liu T, Woo J, International Health Informatics Study N. Frailty and Clinical Outcomes in Advanced Heart Failure Patients Undergoing Left Ventricular Assist Device Implantation: A Systematic Review and Meta-analysis. J Am Med Dir Assoc 2018;19(3):255261 e1.

20. Tse G, Gong M, Nunez J, Sanchis J, Li G, Ali-Hasan-Al-Saegh S, Wong WT, Wong SH, Wu WKK, Bazoukis G, Yan GX, Lampropoulos K, Baranchuk AM, Tse LA, Xia Y, Liu T, Woo J, International Health Informatics Study N. Frailty and Mortality Outcomes After Percutaneous Coronary Intervention: A Systematic Review and Meta-Analysis. J Am Med Dir Assoc 2017;18(12):1097 e1-1097 e10.

21. Skaar E, Eide LSP, Norekval TM, Ranhoff AH, Nordrehaug JE, Forman DE, Schoenenberger AW, Hufthammer KO, Kuiper KK, Bleie O, Packer EJS, Langorgen J, Haaverstad R, Schaufel MA. A novel geriatric assessment frailty score predicts 2-year mortality after transcatheter aortic valve implantation. Eur Heart J Qual Care Clin Outcomes 2019;5(2):153-160.

22. Rogers T, Alraies MC, Moussa Pacha H, Bond E, Buchanan KD, Steinvil A, Gai J, Torguson R, Ben-Dor I, Satler LF, Waksman R. Clinical Frailty as an Outcome Predictor After Transcatheter Aortic Valve Implantation. Am J Cardiol 2018;121(7):850-855.

23. Rockwood K, Song X, MacKnight C, Bergman H, Hogan DB, McDowell I, Mitnitski A. A global clinical measure of fitness and frailty in elderly people. CMAJ 2005;173(5):489-95.

24. Segal JB, Chang HY, Du Y, Walston JD, Carlson MC, Varadhan R. Development of a Claims-based Frailty Indicator Anchored to a Well-established Frailty Phenotype. Med Care 2017;55(7):716-722. 
25. Martin GP, Sperrin M, Ludman PF, deBelder MA, Gunning M, Townend J, Redwood SR, Kadam UT, Buchan I, Mamas MA. Do frailty measures improve prediction of mortality and morbidity following transcatheter aortic valve implantation? An analysis of the UK TAVI registry. BMJ Open 2018;8(6):e022543.

26. Leblanc M, Crowley J. Survival Trees by Goodness of Split. Journal of the American Statistical Association 1993;88(422):457-467.

27. Hothorn T, Bühlmann $P$, Dudoit $S$, Molinaro A, Van Der Laan MJ. Survival ensembles. Biostatistics 2005;7(3):355-373.

28. Steingrimsson JA, Diao L, Molinaro AM, Strawderman RL. Doubly robust survival trees. Statistics in Medicine 2016;35(20):3595-3612.

29. Jaeger BC, Long DL, Long DM, Sims M, Szychowski JM, Min Y-I, McClure LA, Howard G, Simon N. Oblique random survival forests. Ann. Appl. Stat. 2019;13(3):18471883.

30. Hsich E, Gorodeski EZ, Blackstone EH, Ishwaran H, Lauer MS. Identifying important risk factors for survival in patient with systolic heart failure using random survival forests. Circ Cardiovasc Qual Outcomes 2011;4(1):39-45. 
Table 1. Descriptive statistics of the TAVR cohorts

$*_{* *}:<0.001 ; * *:<0.01 ; *:<0.05 ; .:<0.1$

\begin{tabular}{|c|c|c|c|c|c|}
\hline Characteristics & $\begin{array}{l}\text { All patients }(n=450) \\
\text { Median }(I Q R) \text { or count }(\%)\end{array}$ & $\begin{array}{l}\text { Death }(n=22) \\
\text { Median }(I Q R) \text { or count }(\%)\end{array}$ & $\begin{array}{l}\text { Alive }(n=428) \\
\text { Median }(I Q R) \text { or count }(\%)\end{array}$ & $\mathbf{P}$ & \\
\hline \multicolumn{6}{|l|}{ Demographics } \\
\hline Female sex & $221(49.11 \%)$ & $7(31.81 \%)$ & $214(50.00 \%)$ & $0.0026 * *$ & \\
\hline Age at TAVR & $82.3(79.0-86.0)$ & $83.8(81.0-87.0)$ & $82.1(79.0-86.0)$ & 0.261 & \\
\hline Age at first visit & $79(74.0-83.0)$ & $81(78.0-84.0)$ & $79(74.0-83.0)$ & $0.017 *$ & \\
\hline \multicolumn{5}{|l|}{ TR Severity } & $\overline{\bar{\omega}}$ \\
\hline None/trivial & $174(38.66 \%)$ & $7(31.81 \%)$ & $167(39.01 \%)$ & $0.0016^{* *}$ & בై๊ \\
\hline Mild & $177(39.33 \%)$ & $4(18.18 \%)$ & $173(40.42 \%)$ & $<0.0001 * * *$ & $\underset{0}{0}$ \\
\hline Moderate & $78(17.33 \%)$ & $6(27.27 \%)$ & $72(16.82 \%)$ & 0.66 & 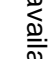 \\
\hline Severe & $21(4.66 \%)$ & $5(22.72 \%)$ & $16(3.73 \%)$ & $0.021 *$ & $\frac{\overline{\bar{\sigma}}}{\bar{\sigma}}$ \\
\hline \multicolumn{5}{|l|}{ AR Severity } & (1) \\
\hline None/trivial & $167(37.11 \%)$ & $9(40.90 \%)$ & $158(36.91 \%)$ & $0.002 * *$ & $\stackrel{0}{\circ}$ \\
\hline Mild & $217(48.22 \%)$ & $9(40.90 \%)$ & $208(48.59 \%)$ & $<0.0001 * * *$ & ֶֶ, \\
\hline Moderate & $60(13.33 \%)$ & $3(13.63 \%)$ & $57(13.31 \%)$ & $<0.0001 * * *$ & W \\
\hline Severe & $6(1.33 \%)$ & $1(4.54 \%)$ & $5(1.16 \%)$ & 0.121 & $\stackrel{2}{\stackrel{2}{+}}$ \\
\hline \multicolumn{5}{|l|}{ MR Severity } & $\frac{0}{5}$ \\
\hline None/trivial & $140(31.11 \%)$ & $4(18.18 \%)$ & $136(31.77 \%)$ & 0.172 & 氶 \\
\hline Mild & $222(49.33 \%)$ & $14(63.63 \%)$ & $208(48.59 \%)$ & $<0.0001 * * *$ & $\begin{array}{l}\overrightarrow{0} \\
\stackrel{0}{0}\end{array}$ \\
\hline Moderate & $75(16.66 \%)$ & $2(9.09 \%)$ & $73(17.05 \%)$ & $<0.0001 * * *$ & 总 \\
\hline Severe & $13(2.88 \%)$ & $2(9.09 \%)$ & $11(2.57 \%)$ & $0.012 *$ & $\begin{array}{l}\overline{\bar{\Phi}} \\
\stackrel{\bar{\Phi}}{\Omega}\end{array}$ \\
\hline \multicolumn{5}{|l|}{ PR Severity } & 胥 \\
\hline None/trivial & $167(37.11 \%)$ & $9(40.90 \%)$ & $158(36.91 \%)$ & $0.021 *$ & \\
\hline Mild & $217(48.22 \%)$ & $9(40.90 \%)$ & $208(48.59 \%)$ & $<0.0001 * * *$ & \\
\hline Moderate & $60(13.33 \%)$ & $3(13.63 \%)$ & $57(13.31 \%)$ & $<0.0001 * * *$ & \\
\hline Severe & $6(1.33 \%)$ & $1(4.54 \%)$ & $5(1.16 \%)$ & 0.123 & \\
\hline Complete recovery & $129(28.66 \%)$ & $0(0.00 \%)$ & $129(30.14 \%)$ & $<0.0001 * * *$ & \\
\hline INR & $1.07(1.0-1.19) ; \mathrm{n}=450$ & $1.32(1.07-2.385) ; \mathrm{n}=22$ & $1.07(1.0-1.17) ; \mathrm{n}=428$ & $<0.0001 * * *$ & \\
\hline \multicolumn{5}{|l|}{ Comorbidities } & \\
\hline
\end{tabular}




\begin{tabular}{|c|c|c|c|c|c|}
\hline Bradyarrhythmia & $23(5.11 \%)$ & $1(4.54 \%)$ & $22(5.14 \%)$ & $<0.0001 * * *$ & \\
\hline Tachyarrhythmia & $34(7.55 \%)$ & $0(0.00 \%)$ & $34(7.94 \%)$ & $<0.0001 * * *$ & \\
\hline Diabetes/Hypertension & $318(70.66 \%)$ & $17(77.27 \%)$ & $301(70.32 \%)$ & $<0.0001 * * *$ & \\
\hline Hyperlipidaemia & $143(31.77 \%)$ & $5(22.72 \%)$ & $138(32.24 \%)$ & $<0.0001 * * *$ & \\
\hline Atrial fibrillation/flutter & $156(34.66 \%)$ & $11(50.00 \%)$ & $145(33.87 \%)$ & $0.0016^{* *}$ & \\
\hline Respiratory & $269(59.77 \%)$ & $16(72.72 \%)$ & $253(59.11 \%)$ & $<0.0001 * * *$ & \\
\hline Kidney & $174(38.66 \%)$ & $12(54.54 \%)$ & $162(37.85 \%)$ & $<0.0001 * * *$ & \\
\hline Endocrine & $23(5.11 \%)$ & $1(4.54 \%)$ & $22(5.14 \%)$ & $0.0172 *$ & \\
\hline Gastrointestinal & $249(55.33 \%)$ & $9(40.90 \%)$ & $240(56.07 \%)$ & $0.016^{*}$ & $\overline{\bar{\omega}}$ \\
\hline \multicolumn{5}{|l|}{ ECG Measurements } & \\
\hline Ventricular Rate & $79(68.0-93.0) ; n=375$ & $95(78.0-109.0) ; \mathrm{n}=17$ & $78(68.0-92.0) ; n=358$ & 0.172 & \\
\hline PWD & $119(109.0-127.0) ; \mathrm{n}=137$ & $89.5(90.0-90.0) ; \mathrm{n}=2$ & $120(109.0-127.0) ; \mathrm{n}=135$ & $<0.0001 * * *$ & \\
\hline PR interval & $173(154.0-196.0) ; \mathrm{n}=290$ & $175.5(146.0-190.0) ; \mathrm{n}=12$ & $173(154.0-196.0) ; \mathrm{n}=278$ & 0.187 & $\frac{5}{0}$ \\
\hline QRS & $98(90.0-110.0) ; \mathrm{n}=375$ & $95(90.0-106.0) ; \mathrm{n}=17$ & $98(90.0-110.0) ; \mathrm{n}=358$ & 0.23 & $=$ \\
\hline QT & $390(358.0-424.0) ; \mathrm{n}=375$ & $379(341.0-402.0) ; \mathrm{n}=17$ & $391(360.0-424.0) ; \mathrm{n}=358$ & $0.012 *$ & $\frac{2}{78}$ \\
\hline QTc & $439(420.0-459.0) ; n=376$ & $449(433.0-471.0) ; \mathrm{n}=17$ & $438(419.0-459.0) ; n=359$ & 0.611 & $\beta^{\omega}$ \\
\hline $\mathrm{P}$-wave axis & $54(30.0-72.0) ; \mathrm{n}=329$ & $49(32.0-94.0) ; n=11$ & $54(30.0-72.0) ; \mathrm{n}=318$ & 0.341 & i \\
\hline QRS axis & $45(22.0-70.0) ; n=375$ & $54(20.0-70.0) ; \mathrm{n}=17$ & $45(22.0-70.0) ; n=358$ & 0.62 & 党 \\
\hline T-wave axis & $71(39.0-115.0) ; \mathrm{n}=372$ & $61(30.0-131.0) ; n=15$ & $72(39.0-115.0) ; \mathrm{n}=357$ & $0.0023 * *$ & o \\
\hline $\mathrm{R}$-wave amp in V5 & $1.87(1.27-2.44) ; \mathrm{n}=236$ & $1.5(1.0-2.0) ; \mathrm{n}=4$ & $1.87(1.28-2.44) ; \mathrm{n}=232$ & 0.102 & $\vec{D}$ \\
\hline $\mathrm{S}$-wave amp in V1 & $1(1.0-2.0) ; \mathrm{n}=235$ & $0.8(0.0-1.0) ; \mathrm{n}=4$ & $0.95(0.526-1.535) ; \mathrm{n}=231$ & 0.081 & \\
\hline \multicolumn{5}{|l|}{ Hospitalization characteristics } & \\
\hline Cumulative LOS & $18(6.0-48.0) ; \mathrm{n}=395$ & $53(10.0-121.0) ; n=19$ & $18(6.0-46.0) ; \mathrm{n}=376$ & $<0.0001 * * *$ & \\
\hline Cumulative no. of admissions & $9(4.0-15.0) ; \mathrm{n}=395$ & $12(4.0-23.0) ; n=19$ & $9(4.0-15.0) ; \mathrm{n}=376$ & $0.0267 *$ & 0 \\
\hline Emergency no. of readmission & $2(1.0-5.0) ; n=155$ & $2.5(1.0-6.0) ; \mathrm{n}=12$ & $2(1.0-4.0) ; n=143$ & 0.261 & \\
\hline \multicolumn{6}{|l|}{ CBC examinations } \\
\hline $\mathrm{MCV}, \mathrm{fL}$ & $90.9(87.0-94.0) ; \mathrm{n}=444$ & $91.4(88.0-96.0) ; \mathrm{n}=22$ & $90.9(87.0-94.0) ; \mathrm{n}=422$ & 0.7512 & \\
\hline Basophil, x10^9/L & $0.02(0.01-0.04) ; \mathrm{n}=393$ & $0.02(0.01-0.025) ; \mathrm{n}=17$ & $0.02(0.01-0.04) ; \mathrm{n}=376$ & 0.97 & \\
\hline Eosinophil, $\times 10^{\wedge} 9 / \mathrm{L}$ & $0.16(0.1-0.27) ; \mathrm{n}=442$ & $0.125(0.0745-0.275) ; \mathrm{n}=22$ & $0.17(0.1-0.27) ; n=420$ & 0.781 & \\
\hline $\mathrm{HbA} 1 \mathrm{C}, \mathrm{g} / \mathrm{dL}$ & $12.2(11.0-14.0) ; \mathrm{n}=444$ & $12(11.0-13.0) ; \mathrm{n}=22$ & $12.2(11.0-14.0) ; \mathrm{n}=422$ & 0.0561 & \\
\hline Lymphocyte, x10^9/L & $1.5(1.1-1.975) ; \mathrm{n}=442$ & $1.08(0.81-1.48) ; \mathrm{n}=22$ & $1.5(1.0-2.0) ; \mathrm{n}=420$ & $<0.0001 * * *$ & \\
\hline
\end{tabular}




\begin{tabular}{|c|c|c|c|c|c|}
\hline Blast, x10^9/L & $0.056(0.0-0.1) ; \mathrm{n}=139$ & $0.045(0.0-0.065) ; \mathrm{n}=12$ & $0.054(0.0-0.1) ; \mathrm{n}=127$ & $0.0281 *$ & \\
\hline Metamyelocyte, x10^9/L & $0.11(0.075-0.19) ; \mathrm{n}=16$ & $0.09(0.055-0.165) ; \mathrm{n}=4$ & $0.115(0.08-0.225) ; \mathrm{n}=12$ & $<0.0001 * * *$ & \\
\hline Monocyte, x10^9/L & $0.45(0.35-0.63) ; \mathrm{n}=442$ & $0.5(0.34-0.6) ; \mathrm{n}=22$ & $0.4(0.0-1.0) ; n=420$ & 0.2711 & \\
\hline APTT, sec & $12.1(11.0-14.0) ; n=439$ & $15.2(12.0-19.0) ; \mathrm{n}=22$ & $12.1(11.0-14.0) ; n=417$ & $<0.0001 * * *$ & \\
\hline Neutrophil, x10^9/L & $4.1(3.14-5.385) ; n=442$ & $4.2(3.0-6.0) ; n=22$ & $4.1(3.0-5.0) ; \mathrm{n}=420$ & 0.271 & \\
\hline WBC, $\times 10^{\wedge} 9 / \mathrm{L}$ & $6.5(5.0-8.0) ; n=444$ & $6.1(5.0-8.0) ; n=22$ & $6.5(5.0-8.0) ; n=422$ & 0.251 & \\
\hline $\mathrm{MCH}, \mathrm{g} / \mathrm{dL}$ & $33.5(33.0-34.0) ; \mathrm{n}=444$ & $33.9(33.0-34.0) ; n=22$ & $33.5(33.0-34.0) ; \mathrm{n}=422$ & 0.325 & \\
\hline Myelocyte, x10^9/L & $0.18(0.105-0.27) ; \mathrm{n}=18$ & $0.17(0.13-0.555) ; \mathrm{n}=3$ & $0.19(0.095-0.27) ; \mathrm{n}=15$ & $0.0182 *$ & $\bar{F}$ \\
\hline Platelet, x10^9/L & $189.5(153.0-232.0) ; \mathrm{n}=444$ & $152.5(130.0-195.0) ; \mathrm{n}=22$ & $190(155.0-233.0) ; n=422$ & $<0.0001 * * *$ & $\bar{\omega}$. \\
\hline Reticulocyte, x10^9/L & $55.2(40.0-79.0) ; n=65$ & $50.6(44.0-77.0) ; \mathrm{n}=5$ & $55.2(39.0-80.0) ; n=60$ & $<0.0001 * * *$ & ڤ్ \\
\hline $\mathrm{RBC}, \mathrm{x} 10^{\wedge} 12 / \mathrm{L}$ & $4.13(3.685-4.52) ; n=444$ & $3.945(3.585-4.45) ; n=22$ & $4.1(4.0-5.0) ; \mathrm{n}=422$ & $<0.0001 * * *$ & $\begin{array}{l}D \\
\stackrel{D}{2}\end{array}$ \\
\hline $\mathrm{HCT}, \mathrm{L} / \mathrm{L}$ & $0.352(0.32-0.39) ; \mathrm{n}=201$ & $0.399(0.3805-0.4095) ; \mathrm{n}=6$ & $0.35(0.32-0.39) ; n=195$ & $0.0207 *$ & 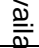 \\
\hline \multicolumn{5}{|l|}{ LRFT examinations } & $\frac{\sigma}{\Phi}$ \\
\hline Potassium, mmol/L & $4.2(4.0-4.0) ; \mathrm{n}=421$ & $4.4(4.0-4.8) ; n=20$ & $4.2(3.8-4.5) ; n=340$ & $<0.0001 * * *$ & 气̆ \\
\hline Urate, $\mathrm{mmol} / \mathrm{L}$ & $0.39(0.32-0.47) ; \mathrm{n}=240$ & $0.43(0.36-0.48) ; \mathrm{n}=16$ & $0.39(0.32-0.47) ; \mathrm{n}=224$ & $0.0016 * *$ & $\stackrel{\mathbb{D}}{\infty}$ \\
\hline Albumin, $g / L$ & $40(37.0-43.0) ; n=445$ & $38.9(36.0-41.0) ; n=22$ & $40(37.0-43.0) ; n=423$ & $0.0121 *$ & ○ \\
\hline Urea, mmol/L & $6.4(5.0-8.0) ; n=445$ & $6.6(6.0-10.0) ; n=22$ & $6.4(5.0-8.0) ; n=423$ & $0.0132 *$ & 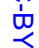 \\
\hline Sodium, mmol/L & $140.1(138.0-142.0) ; \mathrm{n}=360$ & $140.7(139.0-143.0) ; n=20$ & $140(138.0-142.0) ; n=340$ & 0.271 & $\stackrel{+}{0}$ \\
\hline Protein, g/L & $72(68.0-76.0) ; n=400$ & $73.2(67.0-76.0) ; n=20$ & $72(68.0-76.0) ; \mathrm{n}=380$ & 0.835 & $\underset{\equiv}{\bar{D}}$ \\
\hline Creatinine, umol/L & $88.4(71.0-110.0) ; n=445$ & $105.9(78.0-150.0) ; \mathrm{n}=22$ & $88(70.0-108.0) ; n=423$ & $<0.0001 * * *$ & $\frac{\mathbb{1}}{\overbrace{}^{2}}$ \\
\hline ALP, U/L & $70(59.0-86.0) ; \mathrm{n}=445$ & $73.5(64.0-91.0) ; n=22$ & $70(58.0-86.0) ; \mathrm{n}=423$ & 0.356 & 훌 \\
\hline Aspartate Transaminase, U/L & $26(21.0-34.0) ; \mathrm{n}=260$ & $24.8(22.0-32.0) ; n=8$ & $26(21.0-34.0) ; n=252$ & 0.161 & $\stackrel{\varrho}{\equiv}$ \\
\hline $\mathrm{ALT}, \mathrm{U} / \mathrm{L}$ & $18(13.0-24.0) ; n=442$ & $14.5(12.0-19.0) ; \mathrm{n}=22$ & $18(13.0-24.0) ; \mathrm{n}=420$ & $<0.0001 * * *$ & 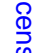 \\
\hline Bilirubin, umol/L & $10.4(8.0-14.0) ; n=445$ & $13(9.0-19.0) ; n=22$ & $10.3(8.0-14.0) ; n=423$ & $0.0015 * *$ & $s$ \\
\hline
\end{tabular}


medRxiv preprint doi: https://doi.org/10.1101/2020.12.23.20248770; this version posted December 28, 2020 . The copyright holder for this preprint (which was not certified by peer review) is the author/funder, who has granted medRxiv a license to display the preprint in perpetuity.

It is made available under a CC-BY 4.0 International license .

Table 2. Univariate regression analysis to identify the predictors of TAVR mortality $* * *:<0.001 ; * *:<0.01 ; *:<0.05 ; .:<0.1$

\begin{tabular}{|c|c|c|c|}
\hline Characteristics & Hazard ratio $(95 \% \mathrm{CI})$ & $Z$ value & $\mathbf{P}$ \\
\hline \multicolumn{4}{|l|}{ Demographics } \\
\hline Female sex & $0.41[0.17,1.01]$ & -1.947 & 0.0515 \\
\hline Age at TAVR & $0.98[0.95,1.02]$ & -1.099 & 0.272 \\
\hline First presentation age & $0.99[0.95,1.02]$ & -0.735 & 0.462 \\
\hline \multicolumn{4}{|l|}{ TR Severity } \\
\hline None/trivial & $0.88[0.36,2.16]$ & -0.278 & 0.781 \\
\hline Mild & $0.38[0.13,1.14]$ & -1.726 & 0.0843 . \\
\hline Moderate & $1.09[0.42,2.86]$ & 0.175 & 0.861 \\
\hline Severe & $8.93[3.22,24.78]$ & 4.203 & $2.64 \mathrm{E}-05^{* * *}$ \\
\hline \multicolumn{4}{|l|}{ AR Severity } \\
\hline None/trivial & $1.38[0.59,3.23]$ & 0.732 & 0.464 \\
\hline Mild & $0.64[0.27,1.50]$ & -1.025 & 0.305 \\
\hline Moderate & $1.10[0.33,3.73]$ & 0.155 & 0.877 \\
\hline Severe & $2.30[0.31,17.27]$ & 0.81 & 0.418 \\
\hline \multicolumn{4}{|l|}{ MR Severity } \\
\hline None/trivial & $0.62[0.21,1.82]$ & -0.877 & 0.381 \\
\hline Mild & $1.68[0.70,4.00]$ & 1.164 & 0.245 \\
\hline Moderate & $0.43[0.10,1.83]$ & -1.144 & 0.253 \\
\hline Severe & $2.79[0.64,12.09]$ & 1.367 & 0.171 \\
\hline \multicolumn{4}{|l|}{ PR Severity } \\
\hline None/trivial & $1.38[0.59,3.23]$ & 0.732 & 0.464 \\
\hline Mild & $0.64[0.27,1.50]$ & -1.025 & 0.305 \\
\hline Moderate & $1.10[0.33,3.73]$ & 0.155 & 0.877 \\
\hline Severe & $2.30[0.31,17.27]$ & 0.81 & 0.418 \\
\hline Complete recovery & - & - & - \\
\hline \multicolumn{4}{|l|}{ Comorbidities } \\
\hline Bradyarrhythmia & $0.87[0.12,6.47]$ & -0.136 & 0.892 \\
\hline Tachyarrhythmia & - & - & - \\
\hline Diabetes/Hypertension & $1.26[0.46,3.44]$ & 0.457 & 0.647 \\
\hline Hyperlipidaemia & $0.64[0.23,1.73]$ & -0.884 & 0.377 \\
\hline Atrial fibrillation/flutter & $7.23[0.96,54.69]$ & 1.917 & 0.055 \\
\hline Respiratory & $1.69[0.66,4.33]$ & 1.095 & 0.274 \\
\hline Kidney & $1.97[0.85,4.57]$ & 1.579 & 0.114 \\
\hline Endocrine & $0.85[0.11,6.32]$ & -0.159 & 0.874 \\
\hline Gastrointestinal & $0.49[0.21,1.16]$ & -1.624 & 0.104 \\
\hline \multicolumn{4}{|l|}{ ECG Measurements } \\
\hline Ventricular Rate & $1.02[1.00,1.03]$ & 2.379 & $0.0174 *$ \\
\hline PWD & $0.94[0.88,1.00]$ & -2.077 & $0.0378^{*}$ \\
\hline PR interval & $0.99[0.97,1.01]$ & -1.059 & 0.29 \\
\hline QRS & $1.00[0.98,1.02]$ & 0.067 & 0.946 \\
\hline QT & $1.00[0.99,1.01]$ & -0.755 & 0.45 \\
\hline QTc & $1.01[1.00,1.02]$ & 2.434 & $0.0149 *$ \\
\hline P-wave axis & $1.00[1.00,1.00]$ & -0.095 & 0.924 \\
\hline QRS axis & $1.00[0.99,1.02]$ & 0.475 & 0.635 \\
\hline T-wave axis & $1.00[0.99,1.01]$ & -0.013 & 0.99 \\
\hline $\mathrm{R}$-wave amplitude in V5 & $0.64[0.22,1.87]$ & -0.823 & 0.411 \\
\hline S-wave amplitude in V1 & $0.54[0.11,2.55]$ & -0.778 & 0.436 \\
\hline \multicolumn{4}{|l|}{ Hospitalization characteristics } \\
\hline Cumulative length-of-stay & $1.01[1.00,1.01]$ & 2.618 & $0.001 * * *$ \\
\hline Cumulative no. of admissions & $1.02[1.00,1.04]$ & 2.161 & $0.031 *$ \\
\hline No. of emergency readmissions & $1.01[0.94,1.10]$ & 0.337 & 0.736 \\
\hline \multicolumn{4}{|l|}{ CBC and clotting examinations } \\
\hline MCV, fL & $1.04[0.97,1.11]$ & 1.076 & 0.282 \\
\hline Basophil, x10^9/L & $0.80[0.02,162.40]$ & -1.524 & 0.127 \\
\hline Eosinophil, $x 10^{\wedge} 9 / \mathrm{L}$ & $0.75[0.10,5.82]$ & -0.271 & 0.786 \\
\hline
\end{tabular}


medRxiv preprint doi: https://doi.org/10.1101/2020.12.23.20248770; this version posted December 28, 2020 . The copyright holder for this preprint (which was not certified by peer review) is the author/funder, who has granted medRxiv a license to display the preprint in perpetuity.

It is made available under a CC-BY 4.0 International license .

\begin{tabular}{|c|c|c|c|}
\hline HbA1C, g/dL & $0.97[0.74,1.28]$ & -0.207 & 0.836 \\
\hline Lymphocyte, $\times 10^{\wedge} 9 / \mathrm{L}$ & $0.33[0.14,0.79]$ & -2.482 & $0.013^{*}$ \\
\hline Blast, $\mathrm{x} 10^{\wedge} 9 / \mathrm{L}$ & $0.08[0.00,19481.00]$ & -0.407 & 0.684 \\
\hline Metamyelocyte, $\times 10^{\wedge} 9 / \mathrm{L}$ & $0.12[0.00,428.20]$ & -0.502 & 0.616 \\
\hline Monocyte, $x 10^{\wedge} 9 / \mathrm{L}$ & $0.62[0.09,4.56]$ & -0.465 & 0.642 \\
\hline APTT, sec & $1.02[1.00,1.04]$ & 1.708 & 0.088 \\
\hline Neutrophil, x10^9/L & $0.99[0.83,1.19]$ & -0.091 & 0.928 \\
\hline $\mathrm{WBC}, \mathrm{x} 10^{\wedge} 9 / \mathrm{L}$ & $0.90[0.71,1.13]$ & -0.933 & 0.351 \\
\hline $\mathrm{MCH}, \mathrm{g} / \mathrm{dL}$ & $1.25[0.84,1.85]$ & 1.094 & 0.274 \\
\hline Myelocyte, x10^9/L & $1.61[0.14,18.84]$ & 0.38 & 0.704 \\
\hline Platelet, $x 10^{\wedge} 9 / \mathrm{L}$ & $0.99[0.98,1.00]$ & -2.164 & $0.0305 *$ \\
\hline Reticulocyte, $\times 10^{\wedge} 9 / \mathrm{L}$ & $0.99[0.96,1.02]$ & -0.543 & 0.587 \\
\hline $\mathrm{RBC}, \times 10^{\wedge} 12 / \mathrm{L}$ & $0.66[0.32,1.37]$ & -1.113 & 0.266 \\
\hline $\mathrm{HCT}, \mathrm{L} / \mathrm{L}$ & $22.00[0.03,31.00]$ & 1.584 & 0.113 \\
\hline INR & $2.74[1.84,4.09]$ & 4.955 & 7.23E-07*** \\
\hline \multicolumn{4}{|l|}{ LRFT examinations } \\
\hline Potassium, mmol/L & $2.54[0.56,5.12]$ & 0.526 & 0.091 \\
\hline Urate, $\mathrm{mmol} / \mathrm{L}$ & $2.23[0.11,43.72]$ & 0.528 & 0.597 \\
\hline Sodium, g/L & $1.25[0.35,2.11]$ & 1.23 & 0.081 \\
\hline Albumin, $g / L$ & $0.95[0.86,1.04]$ & -1.146 & 0.252 \\
\hline Urea, $\mathrm{mmol} / \mathrm{L}$ & $1.08[1.02,1.14]$ & 2.649 & $0.008 * *$ \\
\hline Protein, g/L & $1.02[0.95,1.09]$ & 0.466 & 0.642 \\
\hline Creatinine, umol/L & $1.00[1.00,1.00]$ & 2.469 & $0.014^{*}$ \\
\hline $\mathrm{ALP}, \mathrm{U} / \mathrm{L}$ & $1.01[1.00,1.02]$ & 2.335 & $0.020 *$ \\
\hline Aspartate Transaminase, U/L & $1.01[0.98,1.002]$ & 3.721 & $0.0002 * * *$ \\
\hline ALT, U/L & $1.00[1.00,1.01]$ & 3.282 & $0.001 * *$ \\
\hline Bilirubin, umol/L & $1.02[1.01,1.02]$ & 3.59 & $0.0003 * * *$ \\
\hline
\end{tabular}

Table 3. Multivariate regression analysis to identify the predictors of TAVR mortality

\begin{tabular}{|c|c|c|c|}
\hline Characteristics & Hazard ratio $(95 \% \mathrm{CI})$ & $\mathbf{Z}$ value & $\mathbf{P}$ \\
\hline \multicolumn{4}{|l|}{ Demographics } \\
\hline Age at TAVR & $0.96[0.90,1.04]$ & -1.015 & 0.310 \\
\hline \multicolumn{4}{|l|}{ TR Severity } \\
\hline TR Moderate & $1.75[0.22,13.94]$ & 0.525 & 0.599 \\
\hline TR Severe & $287.30[19.60,429.00]$ & 4.132 & $3.59 \mathrm{E}-05^{* * *}$ \\
\hline \multicolumn{4}{|l|}{ AR Severity } \\
\hline None/trivial & $2.45[0.54,11.14]$ & 1.162 & 0.245 \\
\hline Moderate & $1.49[0.20,10.88]$ & 0.394 & 0.693 \\
\hline Severe & $1.10[0.40,3.21]$ & 0.019 & 0.985 \\
\hline \multicolumn{4}{|l|}{ MR Severity } \\
\hline Mild & $1.83[0.41,8.21]$ & 0.785 & 0.432 \\
\hline Severe & $0.12[0.01,2.96]$ & -1.291 & 0.197 \\
\hline \multicolumn{4}{|l|}{ PR Severity } \\
\hline None/trivial & $1.53[0.18,4.32]$ & 0.7258 & $0.013 *$ \\
\hline Moderate & $1.19[0.06,2.91]$ & 0.1123 & 0.127 \\
\hline Severe & $2.51[1.01,21.81]$ & 0.7743 & 0.349 \\
\hline \multicolumn{4}{|l|}{ Comorbidities } \\
\hline Atrial fibrillation/flutter & $1.28[0.04,2.07]$ & -1.25 & 0.212 \\
\hline Respiratory & $1.01[0.23,4.43]$ & 0.014 & 0.989 \\
\hline Kidney & $0.88[0.20,3.77]$ & -0.176 & 0.860 \\
\hline \multicolumn{4}{|l|}{ ECG measurements } \\
\hline QRS & $0.99[0.96,1.02]$ & -0.596 & 0.551 \\
\hline QT & $0.98[0.97,0.997]$ & -2.402 & $0.016^{*}$ \\
\hline
\end{tabular}


medRxiv preprint doi: https://doi.org/10.1101/2020.12.23.20248770; this version posted December 28, 2020. The copyright holder for this preprint (which was not certified by peer review) is the author/funder, who has granted medRxiv a license to display the preprint in perpetuity.

It is made available under a CC-BY 4.0 International license .

\begin{tabular}{llll}
\hline QTc & $1.03[1.003,1.05]$ & 2.251 & $0.024^{*}$ \\
P axis & $1.01[1.00,1.02]$ & 1.547 & 0.122 \\
QRS axis & $1.00[0.98,1.02]$ & -0.03 & 0.976 \\
T axis & $1.00[0.99,1.02]$ & 0.787 & 0.431 \\
\hline Hospitalization characteristics & & & \\
Cumulative LOS & $1.01[1.00,1.02]$ & 1.234 & 0.217 \\
Cumulative no. of admissions & $1.04[0.95,1.11]$ & 0.950 & 0.342 \\
No. of emergency readmissions & $0.64[0.45,0.92]$ & -2.396 & $0.017^{*}$ \\
\hline CBC and clotting examinations & & & \\
MCV, fL & $1.00[0.89,1.13]$ & 0.029 & 0.977 \\
APTT, sec & $1.02[0.95,1.09]$ & 0.424 & 0.672 \\
MCH, g/dL & $1.79[0.82,3.92]$ & 1.457 & 0.145 \\
Myelocyte, x10^9/L & $0.02[0.002,0.31]$ & -2.852 & $0.004^{* *}$ \\
HCT, L/L & $11.00[8.12,17.26]$ & 2.96 & $0.0001^{* * *}$ \\
INR & $5.30[1.82,15.39]$ & 3.063 & $0.0002^{* * *}$ \\
\hline LRFT examinations & & & \\
Potassium, mmol/L & $2.32[0.05,4.18]$ & 2.315 & $0.027^{*}$ \\
Urate, mmol/L & $0.49[0.00,135.30]$ & -0.247 & 0.805 \\
Urea, mmol/L & $1.27[0.96,1.68]$ & 1.659 & 0.097 \\
Sodium, mmol/L & $1.12[0.87,1.43]$ & 0.891 & 0.399 \\
Protein, g/L & $1.02[0.91,1.14]$ & 0.275 & 0.783 \\
Creatinine, umol/L & $1.0010[0.9880,1.0150]$ & 0.181 & 0.856 \\
ALP, U/L & $1.0140[0.9968,1.0310]$ & 1.591 & 0.111 \\
Aspartate Transaminase, U/L & $1.0120[0.9998,1.0250]$ & 1.929 & 0.053 \\
ALT, U/L & $0.97[0.9239,1.02]$ & -1.296 & 0.195 \\
Bilirubin, umol/L & $0.94[0.8546,1.04]$ & -1.115 & 0.265 \\
\hline
\end{tabular}


medRxiv preprint doi: https://doi.org/10.1101/2020.12.23.20248770; this version posted December 28, 2020. The copyright holder for this preprint (which was not certified by peer review) is the author/funder, who has granted medRxiv a license to display the preprint in perpetuity. It is made available under a CC-BY 4.0 International license .

Figure 1. Kaplan-Meier survival curves of patients undergoing TAVR.

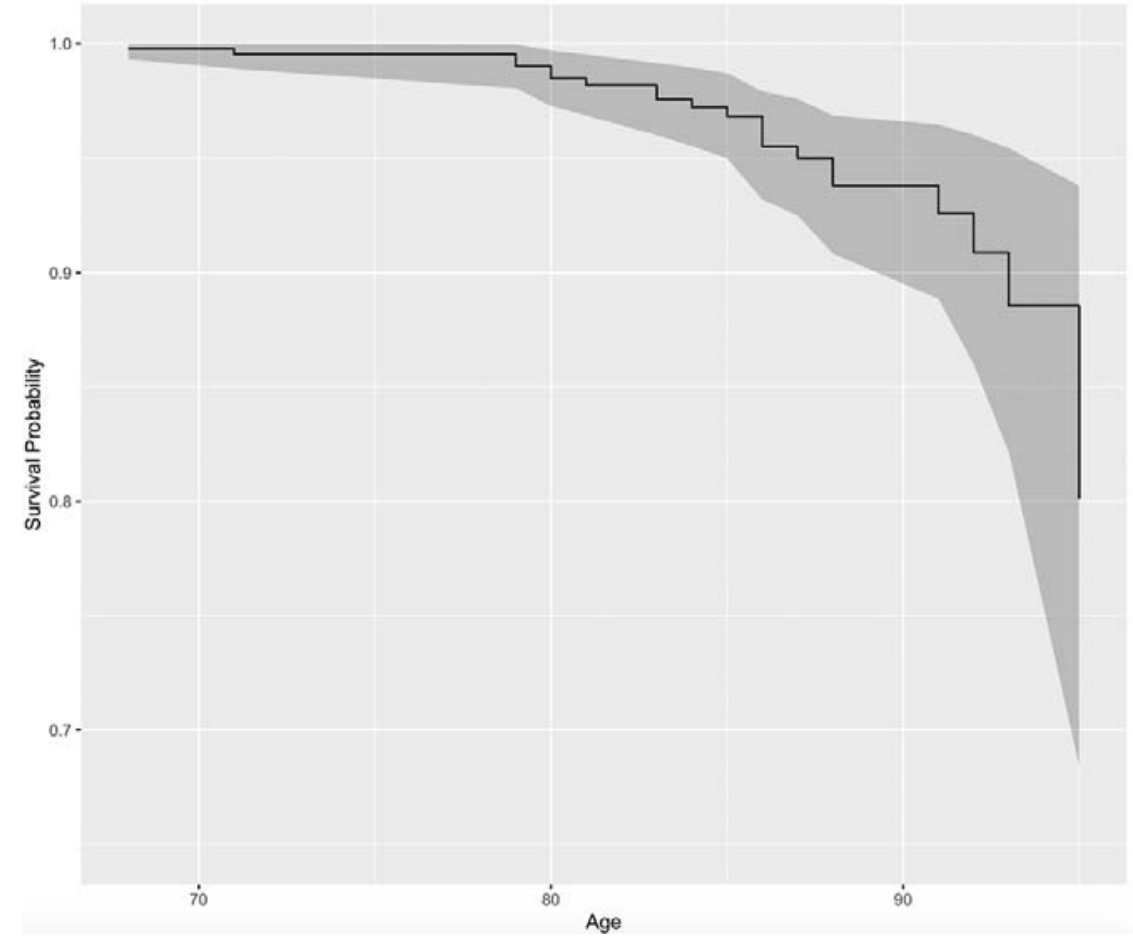

